\title{
Four-Color Sound: A Peircean Semiotics of Comic Book Onomatopoeia
}

\begin{abstract}
Sean A. Guynes
Onomatopoeia are the representation or imitation in language of sounds from the natural world. They occur in the phonic modality of speech, the written modality, and a third modality combining word and image. The latter is a common device in the sequential art of comic strips and comic books, and is particular to the American tradition of comics. Onomatopoeia diversify the experience of sequential art and have unique signifying properties. Though there have been significant attempts to provide a structural analysis of the comics medium, these have often ignored onomatopoeia's uses in the comics medium. This study utilizes the concept of an American Visual Language (Cohn, 2013) within a Peircean framework to offer theories of the individual (onomatopeme) and structural uses of word/image onomatopoeic expressions in mainstream American comic books.
\end{abstract}

Keywords: comics, onomatopoeia, Peircean semiotics, American Visual Language, arthrology

\section{Introduction}

Comics are a multimodal narrative form of sequential art created and enjoyed in distinct manifestations across the world. Comics studies is a relatively recent field of inquiry; as such, specific artistic and narrative phenomena exemplified in comics have been overlooked in favor of approaches that explore the medium as a whole (Groensteen, 2007; Cohn, 2013). Signification of onomatopoeia in comics is therefore underdeveloped, though the graphic representation of onomatopoeic sound has been considered en passant in general discussions (Smolderen, 2006; Groensteen, 2007; Cohn, 2013). Individual essays on the use of onomatopoeia in the Francophone and Japanese comics art traditions have also appeared (Khordoc, 2007; Petersen, 2009). Aside from anecdotes, the narrative and structural use of onomatopoeia in American comic books has yet to be explored.

Comics are the sociocultural context for a structured cognitive system that Cohn (2007, 2013) calls visual language. The "comics" of "comics studies" designates variations in subject matter and genre, (publishing) format, readership and audience expectations, and the histories and artistic traditions that separate, for example, manga from American superhero comics from Franco-Belgian bande desinée from German newspaper strips. ${ }^{1}$ These socio-cultural distinctions in comics art traditions differ on account of their visual repertoires - that is, the lexicon of images and compositional aspects that comics creators use to create comics for individuals who share the same visual language. This shared, linear, and highly conventional set of visual morphemes separates the visual language of comics from non-sequential art (Cohn, 2013, pp. 144147). While idiolectal variations exist, the visual language of American comics-what Cohn $(2013$, pp. 27, 144) refers to as American Visual Language (henceforth: AVL) - is constituted of three dialects: Kirbyan or mainstream AVL, Barksian or cartoony AVL, and independent AVL.

All three dialects of AVL utilize onomatopoeia similarly, if to varying degrees of prevalence. Since the vast majority of comics studies as a discipline is concerned with mainstream and independent AVL, and since the latter dialect utilizes onomatopoeia least frequently, this article provides a Peircean analysis of onomatopoeia in mainstream American comic books, lending a theoretical approach to word/image expressions that

\footnotetext{
${ }^{1}$ Heer and Worcester (2009) provide a useful overview of the diversity of comics traditions and the breadth of research done in the field of comics studies.
} 
punctuate superheroic feats with "whams," "bams," and "pows." Cohn's theory of AVL provides a context for discussing onomatopoeia as stored, shared, morphemic schemata for the visual articulation of sound. In doing so, this article explores the complex prescinding that takes place when a comic book reader interprets an onomatopeme, or the graphic representation of sound as a sign. The process of interpreting onomatopemes requires AVL literacy and an understanding of each individual onomatopoeic sign's relationship to elements at the levels of the comic book narrative (panel, page, issue). General conclusions about onomatopoeia as sign are also offered.

The ideas herein represent research on over one thousand mainstream, mostly superhero, comics published by DC Comics, Marvel, Image, Dark Horse, IDW, America's Best Comics, Big Dog Ink, Boom! Studios, Dynamite Entertainment, and more. A sampling of every tenth comic from an alpha-numeric list of more than 400 comics published in the last four years revealed an average of 11.5 onomatopoeia per comic; a similar sampling of 200 comics from the 1990s revealed a much higher average of 28 onomatopoeia. Averages per comic may change depending on creator, time period, and artistic style, demonstrating that AVL like any language is subject to socio-cultural ideologies and the ebb and flow of linguistic change. Specific examples are limited to one- and two-panel sequential images that articulate poignant aspects of onomatopoeia usage in AVL, and could be easily replaced by dozens of equally illustrative examples.

The study begins by grounding the reader in relevant discussion of onomatopoeia and its use in comics, and offers general ideas about their function in American comic books. The remainder is devoted to defining the signification process and semiotic potential of onomatopemes and to integrating a Peircean analysis of AVL onomatopoeia with current theories of comics art narrative, namely Groensteen's arthrology (2007). Onomatopemes are shown to be highly communicative morphemes. Though not requisite to the comics medium, onomatopoeia aid in the comprehension of sequential art and diversify the multimodal experience of sequential art via a narrative erotics (Petersen, 2009).

\section{Onomatopoeia and comic books}

Onomatopoeia is the representation or imitation in language of sounds from the natural world, rendered according to a language's phonetic inventory, phonological rules, and socio-historical practices. As Bredin (1996, p. 555) claims, "[t]he knowledge of how to speak a language seems to naturally involve a knowledge of whatever principle it is that underlies onomatopoeic idioms, coinings, and usages."2 Using a Peircean model, it has long been established (Lyons, 1977, p. 105; Daniel, 1987, p. 31) that onomatopoeia are iconic signs that refer to their object on the basis of phonic similarity. That is, when someone says "ring ring" " the sound of those words is iconic of the event of a telephone ringing. Onomatopoeia are only iconic in the phonic (i.e. spoken) modality (Lyons, 1977, p. 105); in the graphic or written modality, onomatopoeia are symbols signifying the iconic phonic form, which in turn signify the sound-producer. In written language, therefore, onomatopoeia are involved at least minimally in a two-fold dialogic process of meaning making.

Saussure, too, was troubled by the nature of onomatopoeia. Onomatopoeia's presence in natural human languages necessitated a change in Saussure's conception of arbitrariness, on account of which Saussure stated: "[s]ome signs are absolutely arbitrary;

\footnotetext{
${ }^{2}$ Onomatopoeia is only one type of sound symbolism, which involves different kinds of non-arbitrary soundmeaning mappings (cf. the special issue of PJOS 5(1)).

${ }^{3}$ Throughout this paper, all onomatopoeia will appear in italics. When quoted from some material or, as here, simulated speech, they will also be in quotation marks.
} 
in others we note, not its absence, but the presence of degrees of arbitrariness: the sign may be relatively motivated" (Saussure, 1966, p. 131, his emphasis, quoted in Preucel, 2010 , p. 29). Saussure upheld the relatively arbitrary nature of onomatopoeia by claiming that onomatopoeia are not an organic element of any linguistic system, and once a part of the linguistic system, onomatopoeia undergo the same phonetic and morphological evolution as other lexical items (Bredin, 1996, p. 565; Preucel, 2010, p. 29). Saussure was not all too troubled with onomatopoeia - after all, the phenomenon is relatively limited, at least in the languages Saussure was familiar with.

The onomatopoeia used in AVL predate the comic book, having appeared first in cartoon newspaper strips. Onomatopoeia became popular with Roy Crane's Wash Tubbs of the 1920s. DeForest (2004, p. 116) writes that:

It was Crane who pioneered the use of onomatopoeic sound effects in comics, adding "bam," "pow" and "wham" to what had previously been an almost entirely visual vocabulary. Crane had fun with this, tossing in an occasional "ker-splash" or "lickety-wop" along with what would become the more standard effects. Words as well as images became vehicles for carrying along his increasingly fast-paced storylines.

Before Crane's intervention, a limited visual vocabulary of what Walker (1980) calls indicia gave expression to diegetic sound. ${ }^{4}$ Jagged edges on the border of an image showing an explosion, for example, would symbolize both the sound and physical experience, while z's drawn around a character's head indicated snoring (and, by contiguous relation, the state of sleep). Onomatopoeia in the Crane style were more expressive and helped craft a unique place for sound in graphic representation that extended from the comic strip to the comic books of the 1930s, and remains today.

With very few exceptions contemporary mainstream comic books are a team production, the result of collaboration between a writer, penciler (who draws the outlines of the image), inker (who puts inks to the penciler's outlines), colorist (who adds color to the image), and letterer (who writes or types the words into speech balloons). Who decides which onomatopoeia go into the images differs across artistic teams, though a sampling of comic book scripts shows that typically the writer specifies what "sound effects" should go into the image, leaving its placement and artistic design to the rest of the creative team (Simmons, 2014).

There are two observable types of onomatopoeic expressions used in mainstream comic books. Vocalizations, such as grunts, laughs, or coughs often-but not without exception-appear in the confines of speech boxes. Sound effects, such as explosions, punches, or any sound not imaginably produced by the vocal apparatus, are drawn outside of speech boxes. ${ }^{5}$ Vocalizations are words; sound effects are word/image combinations. Some artists blur the boundaries between vocalization and sound effect onomatopoeia. A memorable scene from Batman: The Killing Joke (Figure 1), drawn by Brian Bolland, features vocalization, sound effects, and vocalization/sound effects. ${ }^{6}$ This, however, is exceptional.

\footnotetext{
${ }^{4}$ By "diegetic" I mean the interior, narrative sphere of a comic, equivalent to the use of the term in film studies to describe the same.

${ }^{5}$ A sound effect onomatopoeia could be conceivably vocalized, for example, if a character says "boom."

${ }^{6}$ All cited images are copyrighted by their respective owners, and are used purely for analytical, critical, and scholarly purposes.
} 

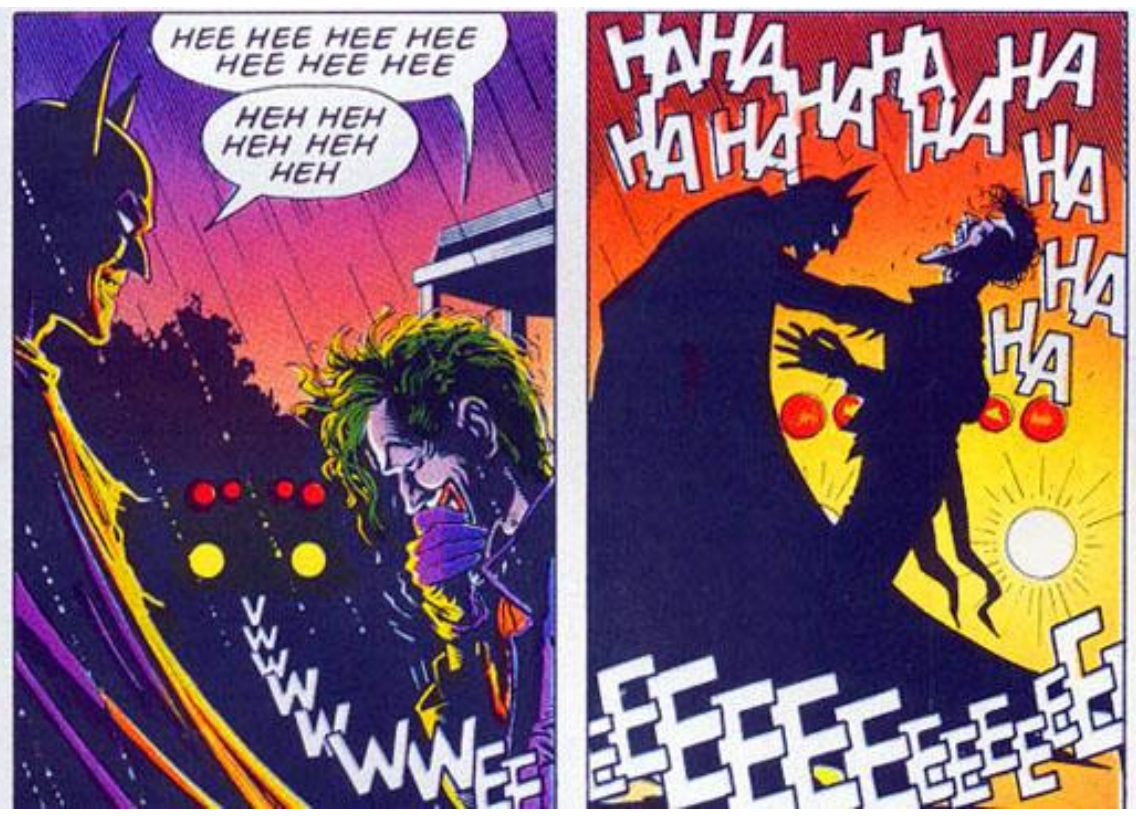

Figure 1. Panels from the final page of Moore and Bolland's Batman: The Killing Joke (1988) (C) DC Comics, Inc.

The careful delineation of two categories of onomatopoeia points to an internal distinction within the comics industry about the nature of graphically represented sound, and perhaps speaks to the limitations of rendering auditory phenomena in non-auditory media. Specifically, it denotes vocalizations as part of the realm of spoken language, since vocalizations rarely take on the properties associated with the sound effect brand of onomatopoeia. Word/image, or sound effect, onomatopoeia are the onomatopoeia that concern a semiotics of visual language.

Onomatopoeia are perhaps the best representative in popular culture of the comic book medium (aside from the famous superheroes and superheroines). Brightly colored block letters reading "pow" or "bang" or "whap" are overlaid on separately, but equally brightly colored geometric designs with jagged edges radiating outward, as in Figure 2, an image of a 1966 TV Guide magazine showing Adam West as Batman. The campy exaggeration of such onomatopoeic designs are a recognizable aspect of AVL, and serve to confirm for many viewers the childishness of comics. Onomatopoeia are nonetheless an integral aspect of the mainstream comics aesthetic; in an attempt to distance themselves from the mainstream, independent comics rarely utilize onomatopoeia. 


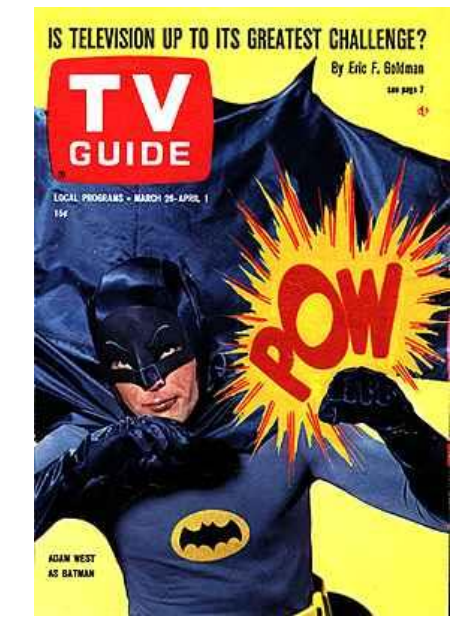

Figure 2. The cover to a 1966 volume of TV Guide

Onomatopoeia are typically called sound effects by comic book creators and readers. Khordoc (2007) has dubbed them visual sound effects and the comic book soundtrack in her study on onomatopoeia in the Franco-Belgian Asterix comics. These terms rely metaphorically on televisual and filmic media by suggesting that onomatopoeia in comic books represent diegetic sound in the same way that sound bites of an explosion or a punch are added to a film's soundtrack to emphasize the actions viewed on the screen. While useful analogies, "sound effects" and "soundtrack" conceive onomatopoeia in comics as indistinguishable units of a system that merely adds dimension to a reader's aesthetic experience of the comic.

Petersen's (2009) preoccupation with Japanese manga innovated the term onomatopoeic sound, distinguishing the representation of sound by Japanese onomatopoeia written into an image from sounds in the natural world. This is an important move toward conceptualizing a semiotics of comic book onomatopoeia. However, the phrase prioritizes sound over its visual expression in the graphic medium, effectively denying the complexity of onomatopoeia's significatory role in sequential art. As Oyola (2011) points out:

\footnotetext{
There is no sound behind that sound. The weak-sounding slaps and smacks of knuckles on flesh would never suffice for the larger than life world of comic superheroes, and the more out-there comics get the more difficult it is to trace a relationship between the textual/visual representation and any sound in the real world... and yet, comic readers not only understand these representations as sound, but there are also a variety of visual clues given that help the reader interpret some quality of those sounds.
}

Oyola identifies comic book onomatopoeia as floating signifiers and in doing so highlights the general concerns of linguists and semioticians regarding onomatopoeia.

To illustrate the point, consider that the sound of an explosion is represented graphically in comic books as "badaboom," "blam," "baroom," "boom," "kaboom," "sssshblam," "krakatoom," or "kapow," among other possible variations. All exhibit similarities attributable to sound-symbolism - e.g. the presence of bilabial and velar plosives and nasals, a lack of high vowels, and a preference for low and/or rounded vowels - and yet none of these onomatopoeia can be falsified as not having the qualities of the sound of an explosion, nor can SOUND OF AN EXPLOSION be definitively explained and linked to a particular phonic equation. Petersen acutely observes that "[t]he lack of possibility in interpreting the sound onomatopoeic word as an actual word with specific 
meanings makes the sound of the word the only meaning the word has to convey in the comic" (Petersen, 2009, p. 164).

The meanings onomatopoeia convey are deferred to other signs by means of indexicality. In an AVL context, onomatopoeia represent diegetic sounds that enliven the reader's experience of the narrative world and call to mind other phenomena, experiences, and sounds in the natural world that further engage the reader. Petersen builds on the work of Susan Sontag and Hans Gumbrecht, and theorizes that comic book onomatopoeia are part of a narrative erotics that "create an animated interior for the story to live within...[a] space for meaning to accrue" $(2009$, p. 165). His narrative erotics of onomatopoeia describes a highly subjective, personal experience that does not explore the individual or structural properties of word/image onomatopoeic expressions in AVL.

\section{The onomatopeme}

The description of any sign or sign type predicates its understanding in the context of a system. An attempt is made here to first describe the prescinding of individual onomatopoeic signs - the onomatopeme - in comic books before describing the way in which they work syntactically as a morphological unit of AVL.

Peircean semiotics with its complex typology of signs allows for scrutiny of the way onomatopemes communicate meaning in comic books. Peirce's triadic sign is composed of the representamen (the sign vehicle), object (that which is intended to be represented), and interpretant (the concept that appears in the mind when the sign is perceived). He describes the relationship between the sign's parts as being on the order of degrees, where the relationship between the sign and its parts may be a firstness (a possibility), secondness (an existent), or thirdness (a law), depending on its qualities of being more individual (i.e. in the mind, "a feeling of red") or more social (i.e. a part of society's rules, the conventions of a system, "a syllogism"). Table 1 presents the sign relations described by Peirce.

Table 1. Peirce's sign relations (copied from Preucel, 2010, p. 56)

\begin{tabular}{c|ccc}
\hline & Sign $\leftarrow \rightarrow$ & Sign $\leftarrow \rightarrow$ & Sign $\leftarrow \rightarrow$ \\
& Representamen & Object & Interpretant \\
\hline Firstness & qualisign & icon & rheme \\
Secondness & sinsign & index & dicent \\
Thirdness & legisign & symbol & argument \\
\hline
\end{tabular}

Peirce identified a typology of at least ten sign-types distinct from one another by virtue of the semiosis the signs undergo, though he speculated that as many as 100 might exist (Preucel, 2010, p. 60; Gorlée, 1994, p. 66). This is further complicated by the supposition that signs do not exist solely as one type or another, but that complex and impossibly quick mental processes decode every level of a sign from the recognition of a possible feeling of pain, to the confirmation that one is in pain, to discovering the argument that the pain was caused by a bee sting.

At the most basic level of interpretation: onomatopoeia in the phonic medium are iconic; in the graphic medium, symbolic, since the sign itself is joined to the object invoked by means of rules governing AVL; and in both, indexical of the natural sound/s being imitated. Cohn (2013) distinguishes between open- and closed-class lexical items, or morphemes, that make up the visual lexicon of AVL. For Cohn, closed-class morphemes in a visual lexicon are those that belong to a set of repeatable, conventionalized signs, particular to and recognizable by those "fluent" in AVL (Cohn, 2013, p. 34-35). Onomatopemes, like speech balloons ("carriers," Cohn, 2013, p. 35) or 
"action stars" (Cohn, 2013, p. 46), are closed-class, since despite idiolectal variation of artists' rendering, onomatopoeia have specific, repeated uses in AVL and cannot easily be extended to include new forms in the way that an open-class AVL morpheme, such as a cartoon of an individual's body, can be drawn with basically limitless variety. As distinct structural units within a system that are defined by convention and that signify a class of objects, onomatopemes are always symbolic legisigns. Following Peirce's explication of the relationship between sign and interpretant, as explained below, whether an onomatopeme is rhematic, dicent, or an argument is governed by its role in an image.

An onomatopeme is rhematic when not acting as part of a system. An onomatopeme alone has meaning, that of whatever sound it is imitative, but it does not play a role in the grammar of a visual composition. Figure 3, an image of Birthday Express's "superhero comics standup city scape," vibrantly illustrates decontextualized, rhematic onomatopemes. Here, they serve merely as a reference to "superhero comics," turning what was an otherwise non-superheroic cardboard display for children into a playground fit for miniature costumed vigilantes.

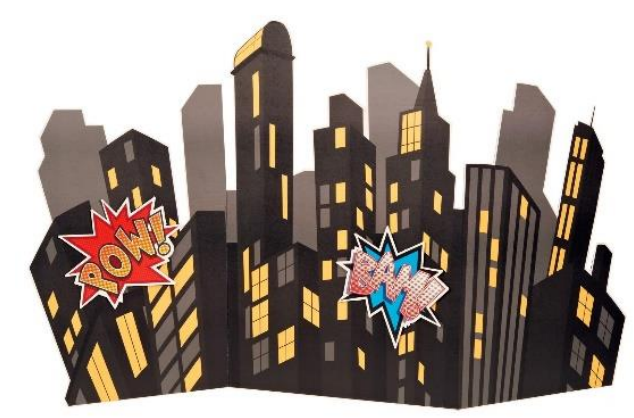

Figure 3. "Superhero Comics Standup City Scape" by Birthday Express (Amazon.com, 2014)

Signs that make propositions are known as dicent symbolic legisigns. These signs propose truth-values ("Batman punched the villain") by associating the rhematic abstraction ("Batman's punch") with a grounding object ("pow"), but do not provide sufficient grounds to confirm or deny their own propositions. Figure 4 provides an example of an onomatopeme contextualized as a visual truth statement in a panel from Batman: Cacophony by Kevin Smith, Walt Flanagan, and Sandra Hope. ${ }^{7}$

\footnotetext{
${ }^{7}$ Fittingly, the villain at the receiving end of Batman's punch, goes by the moniker Onomatopoeia.
} 


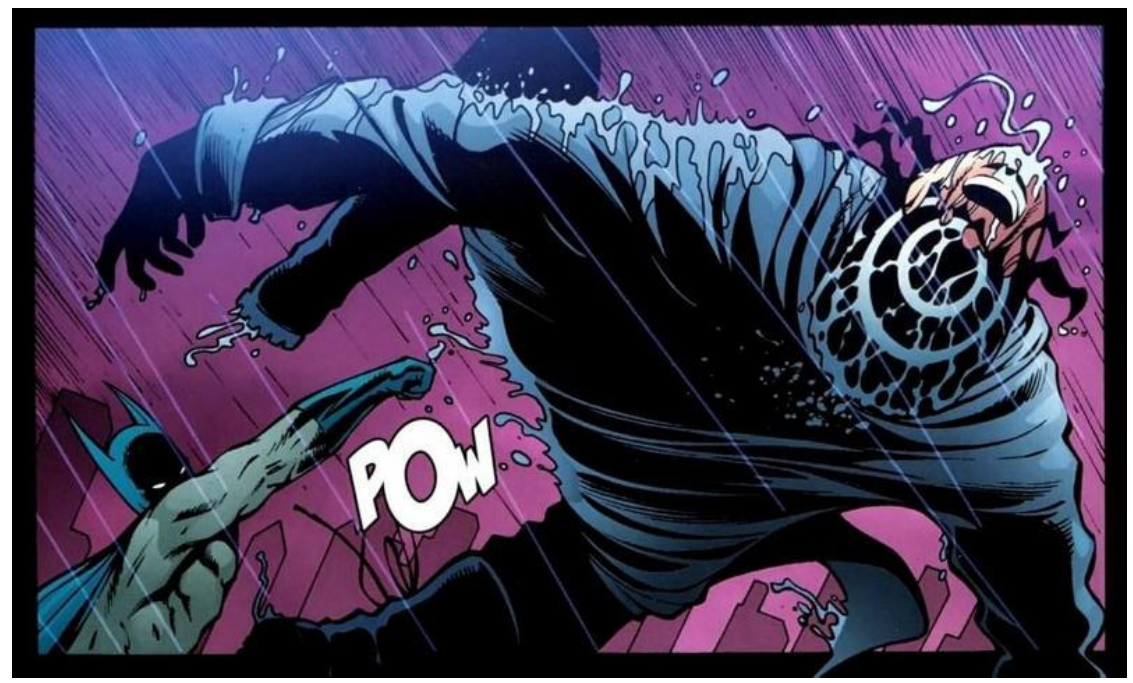

Figure 4. A panel from Batman: Cacophony (Smith and Flanagan, 2010). () DC Comics, Inc.

This image features two figures, one foregrounded and framing with his legs and arm a second figure, Batman. The position of elements may be critical to the cognition of narrative images like those found in comic books, where each image provides narrative thrust on its own and in collective. Kress and van Leeuwen's (1996, p. 208) visual grammar may provide a basis for interpreting narrative images.

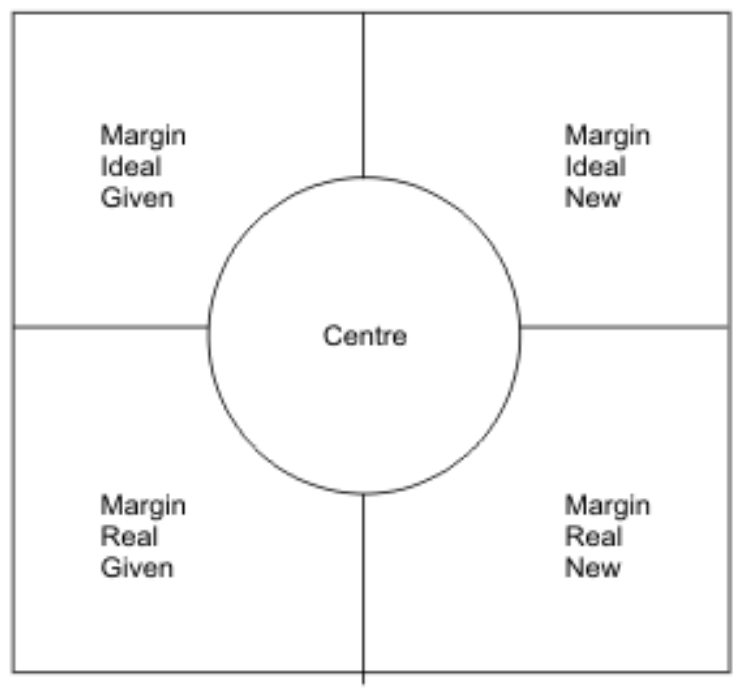

Figure 5. Kress and van Leeuwen's visual grammar (1996, p. 197)

In their study of visual design Kress and van Leeuwen (1996) provide a schema (Figure 5) that they claim to represent a common compositional aesthetic for organizing visual information in the Western art tradition. Kress and van Leeuwen demonstrate the prevalence of Ideal-Real and Given-New axes, mediated or polarized by a center, in visual communication styles ranging from medieval triptychs to contemporary website design. According to their schema, the center provides visual and cognitive focus. The horizontal axis divides the realm of the ideal from that of the real; the vertical divides 
given or old information from new information. Likewise, as Figure 4 shows, a single panel - as a separately constituted image - often displays information along the axes described by Kress and van Leeuwen.

In Figure 4, the center, which is shifted slightly to the left, is occupied by an onomatopeme, "pow," Batman's upraised fist, and the left edge of the foregrounded figure's airborne body. Light — perhaps from a street lamp — shines down from the upper margins (Ideal) and is accompanied by rain; this light casts shadows that darken the underside of the foregrounded figure (Real). The lower margins show a cityscape: the gritty, violent, dangerous Gotham. That Batman's body is intersected by the bottom border of the image, suggests that he is standing. The foregrounded figure straddles the center of both marginal axes. He is not grounded as Batman is. His arms and legs are flailed about, his head is thrown background, and the line of action and his jawline indicate a vanishing point that runs diagonally from the bottom left corner to the top right. This positioning, coupled with Batman's upraised fist-which also follows the vanishing point - suggests that the foregrounded character has been punched. Moreover, his current predicament results from that action, which moves narratively from the left of the image (the fist, the Given) to the right (the prone body, the New).Given to the New, suggesting a cause-effect relationship between the punch and the prone figure.

The action of the narrative occupies the center of the panel in Figure 4, the most dominant element of which is the onomatopeme "pow." "Pow" is recognized in AVL as a word/image expression that conveys PHYSICAL IMPACT, usually of a fist. Throughout AVL, onomatopemes propose that the sound visually presented is the sound of an action within the panel, almost always the sound resulting from a suggested action that takes place near where the onomatopoeia is drawn. In its image-central position the onomatopeme in Figure 4 mediates the relationship between the margins proposed by Kress and van Leeuwen, allowing the reader to understand the Given-New relationship between Batman's fist and the prone figure as being linked, in some way, to the onomatopeme. Ultimately, these contextual and visual cues, organized by the grammar of AVL, motivate the proposition that Batman punched the other figure.

The semiosis of onomatopemes does not end at the dicent legisign, since the dicent symbolic legisign only proposes the truth-value relationship between onomatopeme and other elements of an image. The "pow" in Figure 4 simultaneously acts as an argumentformally called a symbolic legisign argument. The presence of "pow" not only provides the proposition that Batman punched the villain, it also confirms the truth value of the statement. The reader can say, "Yes, Batman punched that man. I know this because of the visual and narrative clues, and because the word "pow" is used to illustrate the sound of Batman punching him."

The simultaneity of proposition and argument is common to onomatopemes, probably because their role in a panel is to focus disparate elements of narrative images (action lines, positioning, marginal composition). Onomatopoeia allow comic book readers to propose and confirm relations between elements in an image. Since onomatopoeia bear narrative significance at the single-panel level, it is worth analyzing them at the level of multi-panel, sequential art narratives.

\section{Onomatopoeia in the System of Comics}

In his ground breaking structural analysis of the comics medium, The System of Comics, Groensteen (2007) argues that the panel serves as the structuring unit of the comic, much in the same way that morphemes are the basic meaningful unit in structural linguistics. He decries Metz's search for the "smallest commutable elements that have a proper meaning" (Groensteen, 2007, p. 3, citing Metz, 1977, p. 155). For Groensteen, the 
discursive relationship between images and text from one panel to another, throughout the entire sequential narrative, causes the panel to be the basic signifying unit for the reader. Consider, for example, Figure 6, a typical comic book page composed of multiple panels, the sequence of which drives forward the narrative from left to right, from top tier to bottom tier.

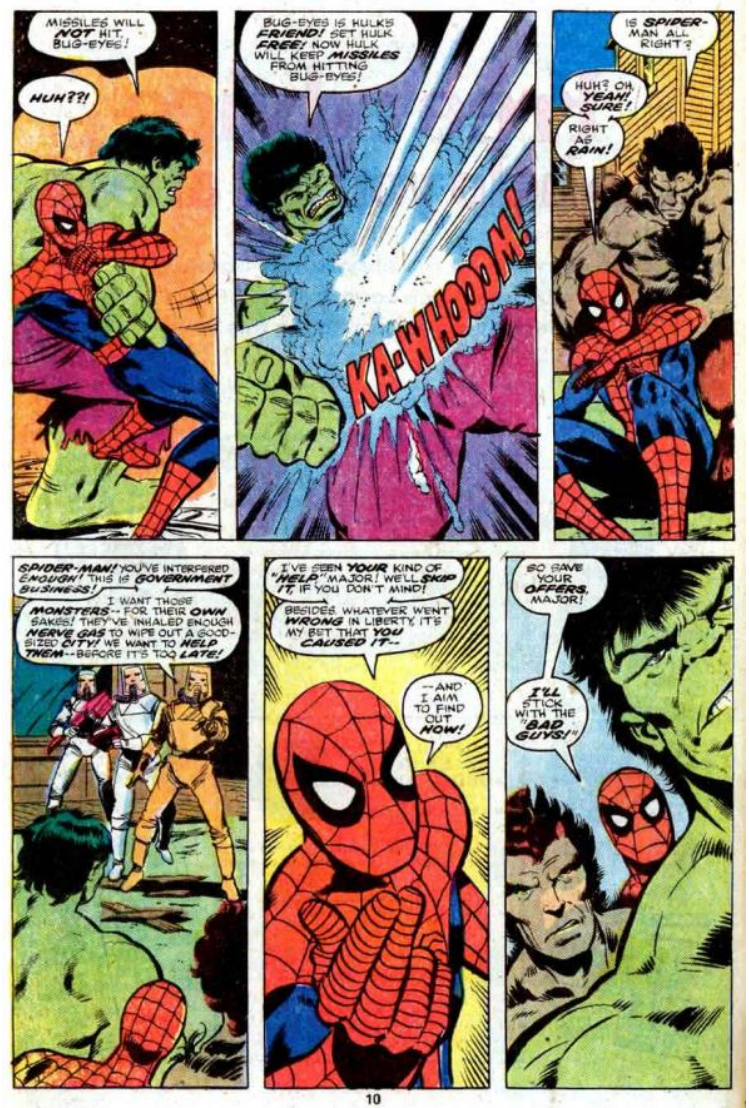

Figure 6. A page from Marvel Team-Up \#54 (Mantlo, Byrne, \& Esposito, 1977). () Marvel Worldwide, Inc.

Groensteen calls his theory of the relationship between panels the system of comics. He postulates that comics are a blend of dynamic and static media. Whereas film is dynamic, composed of editorially-combined sequences of shots over the course of which narration progresses regardless of whether viewers want it to or not, the written word is static, and it only progresses in narration as a result of the reader's agency. Comics, however, are both-they are a compilation of static images which suggest dynamicity through their relationship to other static images. The suggested dynamicity is a result of what Groensteen calls arthrology, or the (study of) significatory relationships between (all) panels.

Groensteen (2007) showed comics to be a primarily visual species of narration, and established arthrology as a method of studying the linear and distant relationships between panels. Despite his advancements to the field, Groensteen's panel-centric concern with arthrology leads him to completely ignore the narrative potential of onomatopoeia and other sub-panel elements to interact beyond their panels.

Groensteen's holistic interpretation of basic units in comics is opposed to more atomistic views like that espoused by Gauthier (1976, p. 113). 
We postulate there that, in every image [of a comic], it is possible to isolate lines or groups of lines, spots or groups of spots, and to locate, for each signifier thus determined, a precise signified, itself corresponding to a part of the global signifier [the panel].

Groensteen labels Gauthier's approach "micro-semiotic," since it is interested in the tracing the smallest constituent unit of any image, for example a single line that in and of itself has no meaning but which operates much as a phoneme in making up a morpheme (Groensteen, 2007, p. 5). For Groensteen, however, the panel is the foundational unit of a language of comics, composed of smaller "codes" (i.e. the images and signs, like onomatopoeia or speech balloons, which make up the panel (Groensteen, 2007, p. 3-6)). Cohn (2013, pp. 67-68) finds Groensteen's system of comics to be a useful theory for understanding the relationships between panels, but nothing more. Cohn's theory of AVL relies on the morphemic and compositional elements of individual panels as much as it does on the global relationship between panels organized in simultaneous narrative, event, and navigational structures (ibid., p. 13). This is because elements of a panel often contain information vital to decoding the relationship between that panel and another. Analyzing morphemes of AVL motivates and deepens Groensteen's arthrology.
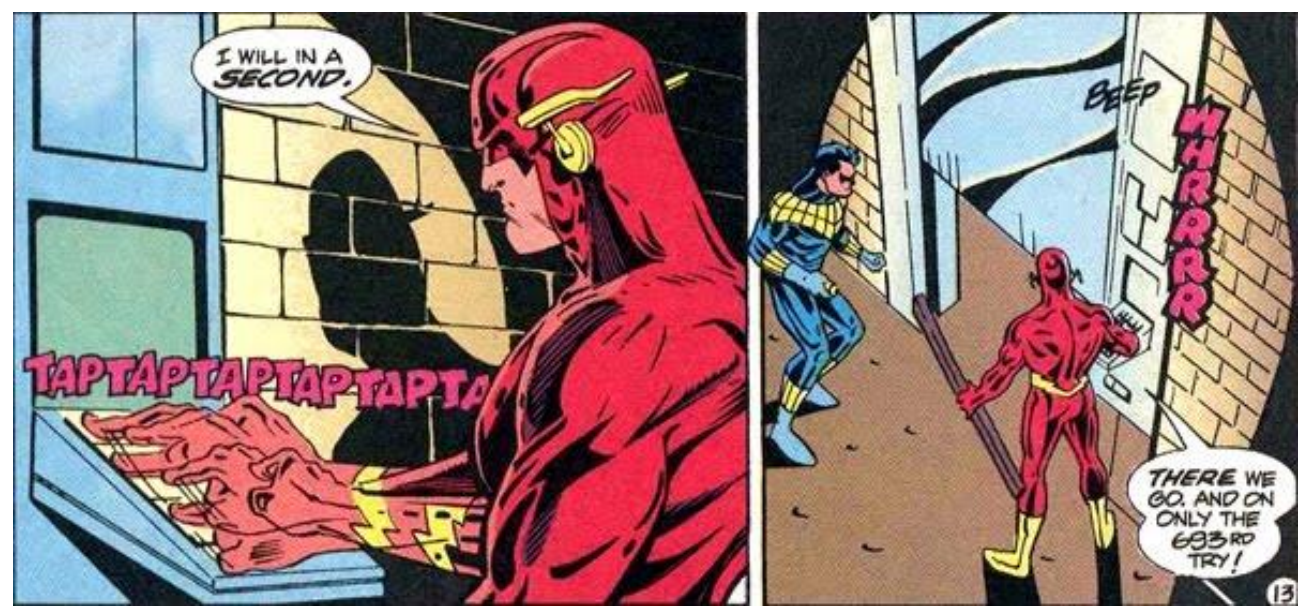

Figure 7. Linear panels from The Flash \#82 (Waid and Wieringo, 1993). (C DC Comics, Inc.

Figure 7 is an excellent example of onomatopemes' importance to the arthrology. In these linear panels from The Flash \#82 (Waid, Wieringo and Marzan, 1993), onomatopemes articulate the narrative structure at work in the separate images. In the first panel, The Flash's hand moves at lightning-fast speed over a computer keyboard, the sound of which is illustrated by the onomatopoeia "taptaptaptaptapta." Comics artists typically render fast, repetitive, or continued movement by drawing multiple, overlapping outlines of the object in motion - Cohn dubs this AVL morpheme suppletion (2013, p. 44). The onomatopeme establishes an auditory/physical relationship between the suppletion and the computer keyboard by means of the signifying mode of the dicent symbolic legisign and the argument.

In the second panel, The Flash and another hero, Nightwing, are shown standing in front of a door that is halfway open, with the onomatopoeia "whrrrr" drawn vertically near the door, and a smaller "beep" horizontally intersecting the door and the doorjamb. The Flash says, "There we go, and on only the $693^{\text {rd }}$ try!" The Flash's speech and the "beep" (SOUND OF TECHNOLOGY) represent the effect for the cause in the first panel, while the "whrrrr" proposes that the door is opening. A linear arthrological relationship between first and second panels give this truth value. Figure 7 is a great example of 
onomatopemes at work in the arthrology beyond their home panels. It shows that panel one proposes and evaluates diegetic action that has narrative bearing on panel two.

Moreover, Figure 7 demonstrates the bound nature of onomatopemes as they combine with the meaningful constituents units of a panel to create arthrological relations among other panels. Cohn understands the "bound morphemes" of AVL to be those signs in an image that "cannot exist independently of a root object that they are modifying" (Cohn, 2007, p. 48). Like a speech balloon-what Cohn calls a "carrier" (Cohn, 2007; 2013) - an onomatopeme requires some root object from which its meaning in the panel can be understood. Of course, highly conventionalized onomatopoeia such as "pow" or "beep" are almost always understood to mean what they signify without a root-object context, as demonstrated by the onomatopemes in Figure 3. However, in the context of comic book panels, onomatopemes are bound to some root object that represents a diegetic event that can be thought to have caused the sound. In Figure 7, "taptaptaptaptapta" and "whrrrr" are understood as described above only because they are bound to root objects-namely, the Flash's hands typing at the keyboard and the electronically inflected opening of a door, respectively.

A negative review of Titans \#27 (Wallace and Fiorentino, 2010) on InsidePulse.com's "Comics Nexus" page attests to the importance of the signifying role of onomatopoeia in the arthrology. The reviewer comments (Little, 2010) on a panel in which the character catches ("catch"), then throws, three spear-like objects. "The comment attached to the image provided in the review is telling: "But...there's no 'throw' sound effect. For all I know, he threw them with his mind!" (Figure 8). This statement points out that the artistic choice to associate an onomatopeme is relevant to the movement of action along the given-new marginal axis of the image (Kress and van Leeuwen, 1996). This is especially important in an image that portrays two events simultaneously, where the onomatopeme is bound to elements in the given margin. Readers cannot accurately assess the panel as a unit within the arthrology. Little's commentary also reminds artists and semioticians that readers actively consider the elements of panels and their arthrology, and that they make judgments about the quality and use of onomatopoeic signs.

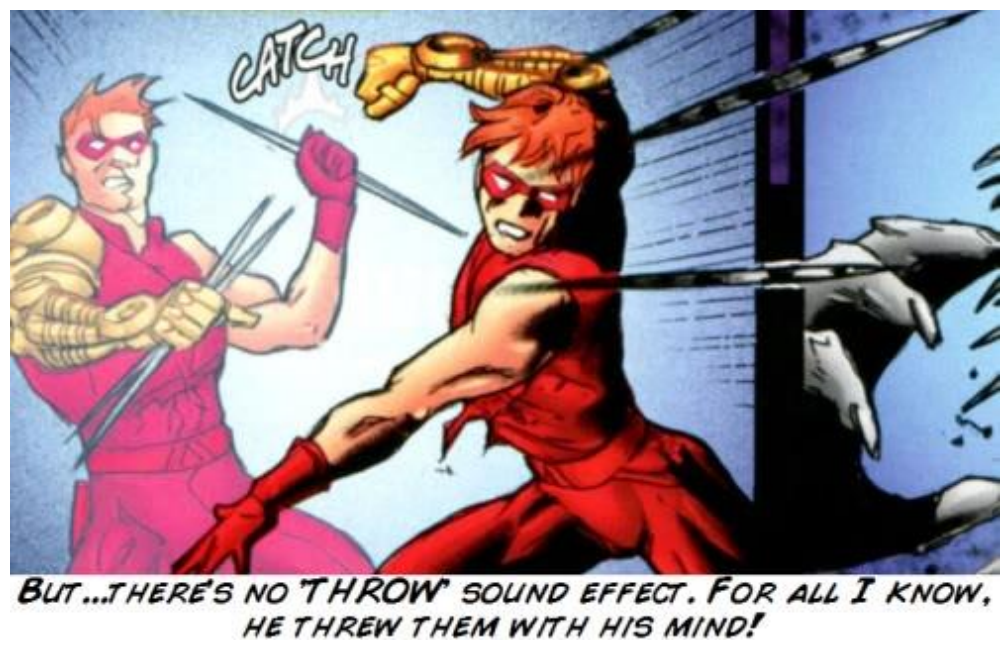

Figure 8. Panel from Titans \#27 (2010) with reviewer commentary (Little 2010). (C) DC Comics, Inc.

\footnotetext{
${ }^{8}$ Walker (1980: 46) calls it "cheating" when an artist uses the word for the action invoked as the onomatopoeia itself. His example is a figure digging, with the onomatopoeia "dig dig dig dig dig dig" above the figure's head.
} 


\section{Conclusion}

By showing the arthrological importance of onomatopemes and their ability to propose and evaluate information at the level of the panel and beyond, this article does not mean to conclude that onomatopemes are the key signifying unit of comics. They are, however, rich with significatory potential, enlivening what are otherwise static images in a sequence suggestive of dynamicity. Groensteen's (2007) focus on the panel is indicative of its primal importance to the medium. This is indicated by the fact that onomatopemes work as part of the system of comics, as grammatical units bound to images within the panels that organize the medium and which can be taken account of systematically.

Onomatopemes are not required by the comics medium. Khordoc (2007) and Petersen (2009) provide evidence of two different visual languages - the Franco-Belgian bande desinée and the Japanese manga - that represent diegetic sound in an entirely different ways. Onomatopemes as described here are descriptive of a mainstream AVL that characterizes American superhero comics like those published by Marvel and DC Comics.

This study provides a Peircean analysis of comic book onomatopoeia insofar as they can be understood within the visual language proposed by Cohn (2013). In a complex patterning of semiosis, comic book onomatopoeia embody all meaning-making modes of Peirce's thirdness, and as signs they indexically suggest the sounds in the real world which they purport (by symbolism) to signify. Onomatopemes are indexical (by virtue of contiguous spatial relations in a panel) and symbolic (by virtue of the dicent legisign and argument). They are morphemes bound to the images in a panel, structured in sequence to relate a narrative. The reader who encounters an instance of onomatopoeia in a comic book should be pleasantly surprised that, in a matter of seconds, their mind unravels the semiotic web of onomatopemes in such a way that the graphic medium's elaborate means of conveying the type and quality of sound "without recourse to adjectives" becomes nearly invisible (Oyola, 2011). Unlike most other aspects of AVL, onomatopemes invoke a narrative erotics that encourages readers to embody the diegesis (Petersen, 2009).

Future studies should follow Cohn (2013) in using cognitive psychological experiments to corroborate the interpretations put forward here, and should look beyond AVL to investigate comparative uses of diegetic sound in other visual languages. While this study provides limited data that hints at a decline in the average use of onomatopoeia in the last three decades, further evidence on the historical development of onomatopoeia in AVL and across artistic styles would benefit the study of the comics medium. In general, such a study might provide insight into the historical development of visual language lexicons.

\section{Acknowledgments}

Profound thanks to Dr. Judith M.S. Pine of Western Washington University who introduced me to semiotics and whose courses served as a testing ground for my discussion of comic books alongside the theories of C.S. Peirce. Thank you to my partner for her support while I wrote this, and to Robin Engström, Dr. Jordan Zlatev, and the anonymous reviewers at The Public Journal of Semiotics for fielding my article and offering their formative critique. 


\section{References}

([*] contains visual reference)

Amazon.com (2014). Birthday Express - superhero comics standup city scape. Amazon.com. Retrieved from http://www.amazon.com/dp/B00CTSGTWE/. [*]

Bredin, H. (1996). Onomatopoeia as a figure of speech and a linguistic principle. In New Literary History, 27.3, 555-569.

Cohn, N. (2007). A visual lexicon. In The Public Journal of Semiotics, 1.1, 35-56.

Cohn, N. (2013). The Visual Language of Comics: Introduction to the Structure and Cognition of Sequential Images. Bloomsbury Advances in Semiotics. New York: Bloomsbury.

Daniel, V. (1987). Fluid Signs: Being a Person the Tamil Way. Berkeley: University of California Press.

DeForest, T. (2004). Storytelling in the Pulps, Comics, and Radio: How Technology Changed Popular Fiction in America. New York: McFarland.

Gauthier, G. (1976). Les Peanuts: un graphisme idiomatique. In Communications, 24, $108-139$.

Gorlée, D.L. (1994). Semiotics and the Problem of Translation: With Special Reference to the Work of Charles S. Peirce. Amsterdam: Rodopi B.V.

Groensteen, Th. (2007). B. Beaty and N. Nguyen (Trans). The System of Comics. Jackson, MS: University of Mississippi Press.

Heer, J., \& Worcester, K. (Eds). (2009). A Comics Studies Reader. Jackson, MS: University Press of Mississippi.

Khordoc, C. (2007). The comic book's soundtrack: Visual sound effects in Asterix. In R. Varnum and C.T. Gibbons (Eds.), The Language of Comics: Word and Image (pp.156-173). Jackson, MS: University of Mississippi Press.

Kress, G. \& van Leeuwen, Th. (1996). Reading Images: The Grammar of Visual Design. New York: Routledge.

Little, Z. (2010). REVIEW: Titans \#27 by Eric Wallace. InsidePulse.com. Retrieved from http://insidepulse.com/2010/09/26/review-titans-27-by-eric-wallace/. [*]

Lyons, J. (1977). Semantics. Volume 1. Cambridge: Cambridge University Press.

Mantlo, B., Byrne, J., \& Esposito, M. (1977). Marvel Team-Up, 54. New York: Marvel Comics Group. [*]

Metz, C. (1977). Langage et cinema. Paris: Albatross.

Moore, A., \& Bolland, B. (1988). Batman: The Killing Joke. New York: DC Comics. [*]

Oyola, O. (2011). This is not a sound: The treachery of sound in comic books. Sounding Out: The Sound Studies Blog. Retrieved from http://soundstudiesblog.com/2011/06/ 13/this-is-not-a-sound-the-treachery-of-sound-in-comic-books/.

Petersen, R.S. (2009). The acoustics of manga. In J. Heer and K. Worcester (Eds.) A Comics Studies Reader (pp.163-171). Jackson, MS: University Press of Mississippi.

Preucel, R.W. (2010). Archaeological Semiotics. Malden, MA: Wiley-Blackwell.

Simmons, T. (2014). Comic book script archive. Comics Experience. Retrieved from http://www.comicbookscriptarchive.com/archive/the-scripts/.

Smolderen, Th. (2006). Of labels, loops, and bubbles: Solving the historical puzzle of the speech balloon." In Comic Art, 8, 90-112.

Saussure, F. de (1966). W. Baskin (Ed. and trans.). Course in General Linguistics. New York: McGraw-Hill.

Waid, M., Wieringo, M., \& Marzan, J. (1993). The Flash, 82. New York: DC Comics. [*]

Walker, Mort. (1980). The Lexicon of Comicana. Port Chest, NY: Museum of Cartoon Art.

Wallace, E. \& Fiorentino, F. (2010). Titans, 27. New York: DC Comics. [*] 
Public Journal of Semiotics 6(1)

\author{
Author address \\ Sean A. Guynes \\ M.A. Student \\ Department of American Studies \\ University of Massachusetts Boston \\ 100 Morrisey Blvd, Boston, MA 02124 \\ saguynes@jphaas.net
}

About the author

Sean A. Guynes is a graduate student in American Studies at the University of Massachusetts Boston; he is currently applying to Ph.D. programs while finishing his master's project, "Fatal Attractions: The AIDS Crisis and Homophobia in Mainstream American Comics, 1988-2005." His primary scholarly investment is the history and theory of literary, graphic, and filmic genres of the 20th and 21st centuries, especially speculative fiction and comics. 